\title{
Carbon-hydrogen bond activation over tungsten carbide catalysts
}

\author{
Kendrick E. Curry, Levi T. Thompson* \\ Department of Chemical Engineering, The University of Michigan, Ann Arbor, Michigan 48109-2136, USA; \\ fax. $(+1-313) 7630459$
}

\begin{abstract}
Tungsten carbides with surface areas ranging from 4 to $39 \mathrm{~m}^{2} / \mathrm{g}$ were prepared by the temperatureprogrammed carburization of tungsten oxide and nitride powders with pure $\mathrm{CH}_{4}$ or a $48.9 \% \mathrm{CH}_{4}$ in $\mathrm{H}_{2}$ mixture. Oxygen uptakes on the carbides were low most likely because of the presence of graphitic carbon at the surface. Nevertheless, the carbides were active and selective for the dehydrogenation of butane at temperatures between 623 and $723 \mathrm{~K}$ and atmospheric pressure with and without $\mathrm{H}_{2}$ in the reactant feed. With $\mathrm{H}_{2}$ in the feed, the higher surface area carbides $\left(\geq 36 \mathrm{~m}^{2} / \mathrm{g}\right)$ were as active as a $\mathrm{Pt}-\mathrm{Sn} / \gamma-\mathrm{Al}_{2} \mathrm{O}_{3}$ catalyst, but their selectivities were different. Without $\mathrm{H}_{2}$ in the feed, the selectivities of the carbides were similar to those of the $\mathrm{Pt}-\mathrm{Sn} / \gamma-\mathrm{Al}_{2} \mathrm{O}_{3}$ catalyst, but their reaction rates were 1-3 orders of magnitude lower. The high surface area materials were also active for the hydrogenolysis of butane. Because the catalytic properties of the carbides varied with the average particle size, we concluded that butane dehydrogenation was structure-sensitive over these materials, and suspected that this behavior was due to variations in the surface stoichiometry as well as the particle faceting.
\end{abstract}

\section{Introduction}

Striking similarities have been reported between the catalytic properties of $\mathrm{W}$ carbides and Pt group metals for hydrocarbon conversion reactions including dehydrogenation [1-3], isomerization [3-8] and hydrogenolysis [2,3,5-8]. Early studies indicated that the selectivities over low surface area carbides were similar to those over supported Pt group metals for the reactions of neopentane, $n$-hexane, $n$ heptane and cyclohexane, but the reaction rates were $1-4$ orders of magnitude lower [2-4]. Recent advances in the synthesis of high surface area materials have led to the preparation of carbides with reaction rates comparable to those of $\mathrm{Pt}$ group metals for the aforementioned reactions [5-8]; however, their selectivities are

\footnotetext{
* Corresponding author.
} 
typically different. There is evidence that the preparation conditions affect the surface composition $[2,8]$. The carbon stoichiometry in the carbide lattice in turn influences the catalytic and electronic properties [9-11]. Nonstoichiometric carbides have been reported to be active for the dehydrogenation of cyclohexane and hydrogenation of propene $[2,12]$. We believe that both the stoichiometry and structure control catalytic function. While some structure-function information is available, detailed relationships between the structure, stoichiometry and catalytic properties of $\mathrm{W}$ carbides have not been presented.

In this paper, we describe the structural, compositional and functional properties of $\mathrm{W}$ carbide catalysts with a range of surface areas. These catalysts were prepared by the temperature-programmed carburization (TPC) of W oxide and nitride precursors. This is an effective technique for manipulating solid state reaction events like particle nucleation and growth. Butane dehydrogenation was used as the test reaction. This reaction is of importance in the petroleum refining and synthetic rubber industries. Characterization techniques including $\mathrm{X}$-ray diffraction and $\mathrm{O}_{2}$ chemisorption were employed to evaluate the structural and sorptive properties of these catalysts.

\section{Experimental}

\subsection{Synthesis}

A series of $\mathrm{W}$ carbides was prepared via the TPC of $\mathrm{W}$ oxide and nitride precursors. Different heating rates $(\beta), \mathrm{H}_{2}$ to $\mathrm{CH}_{4}$ ratios $\left(\mathrm{H}_{2} / \mathrm{CH}_{4}\right)$, and $\mathrm{CH}_{4}(99.99 \%$, Scott) weight hourly space velocities (SV) were used in an effort to vary the carbide structural and compositional properties. The $\mathrm{CH}_{4}$ weight hourly space velocity is defined as the mass flow-rate of $\mathrm{CH}_{4}$ divided by the mass of catalyst precursor.

Typically, a plug of quartz wool was packed onto a frit inside a quartz reactor ( $15.88 \mathrm{~mm}$ OD) fitted with a cooling water jacket. Between 1 and $5 \mathrm{~g}$ of $\mathrm{WO}_{3}$ (99.7\%, Alfa), $\mathrm{H}_{2} \mathrm{WO}_{3}\left(99 \%\right.$, Aldrich), or $\left(\mathrm{NH}_{4}\right)_{10} \mathrm{~W}_{12} \mathrm{O}_{41} \cdot 5 \mathrm{H}_{2} \mathrm{O}(99.999 \%$, Johnson Matthey) was spread over the plug in the form of a thin bed. The reactor bed was then placed in a furnace (Thermcraft Model 132) connected to a temperature controller (Omega CN-2010). The flow-rates of $\mathrm{CH}_{4}$ or $\mathrm{CH}_{4}$ in $\mathrm{H}_{2}$ were set so that $\mathrm{CH}_{4}$ space velocities of 1.27 to $7.77 \mathrm{~h}^{-1}$ were obtained. The gas flow-rates were measured using calibrated rotameters and controlled using needle valves. After establishing the flow-rates, a chromel-alumel ( $\mathrm{K}$ type) thermocouple was secured against the outside wall of the reactor, and the furnace was closed.

Two temperature programs were employed for preparation of the catalysts. In the first program, the temperature was increased from room temperature to $943 \mathrm{~K}$ in 0.5 hours then from $943 \mathrm{~K}$ to $1153 \mathrm{~K}$ at 60 or $120 \mathrm{~K} / \mathrm{h}$. In the second program, the temperature was increased from room temperature to $973 \mathrm{~K}$ at 60 or $120 \mathrm{~K} / \mathrm{h}$. 
In both cases, the reactant mixture was held at the final temperature for 1 hour. These synthesis conditions bracketed those employed previously [13,14]. After synthesis, the furnace was opened and the bed was rapidly cooled to room temperature in $\mathrm{He}$ (99.99\%, Air Products). Before exposure to air, the materials were passivated with a mixture of $0.996 \% \mathrm{O}_{2}$ in $\mathrm{He}$ ( Scott).

A tungsten carbide catalyst was prepared also via the topotactic carburization of tungsten nitride [15]. The nitride was prepared in a fashion similar to that used to produce the carbides from $\mathrm{WO}_{3}$. About $4 \mathrm{~g}$ of $\mathrm{WO}_{3}$ was reacted with anhydrous ammonia ( $99.998 \%$, Scott) flowing at a space velocity of $1.08 \mathrm{~h}^{-1}$. The temperature was increased from room temperature to $673 \mathrm{~K}$ in 0.5 hours, then to $873 \mathrm{~K}$ at 67 $\mathrm{K} / \mathrm{h}$ and finally to $1023 \mathrm{~K}$ at $75 \mathrm{~K} / \mathrm{h}$. After completion of the nitridation, the bed was rapidly cooled to room temperature in flowing He. The material was exposed to flowing $\mathrm{CH}_{4}$ at room temperature so that a space velocity of $1.01 \mathrm{~h}^{-1}$ was obtained. The temperature was increased to $828 \mathrm{~K}$ in 0.5 hours and finally to 1128 $\mathrm{K}$ at $75 \mathrm{~K} / \mathrm{h}$. After completion of the temperature program, the bed was quenched to room temperature in $\mathrm{He}$, and the product was passivated. Carbides with surface areas as high as $100 \mathrm{~m}^{2} / \mathrm{g}$ have been prepared via the TPC of W nitrides $[14,15]$.

\subsection{Characterization}

The bulk properties of the materials were characterized using a computer controlled Rigaku Rotaflex DMAX-B rotating anode X-ray diffractometer with a Cu $\mathrm{K} \alpha$ radiation source. The structure of the material was determined by comparing the patterns to those found in the Powder Diffraction Files (ICDD) [16]. We used line broadening analysis based on the most intense peak in the diffraction pattern to determine the average crystallite size. The crystallite size, $D_{\mathrm{c}}$, was estimated using the Scherrer equation [17]. The ratio of the intensities of the two most intense peaks in the patterns were used to assess preferential orientation of the crystallites.

The bulk compositions of the materials were estimated using a Perkin-Elmer $2400 \mathrm{CHN}$ analyzer equipped with an autosampler. Between $2-5 \mathrm{mg}$ of sample was placed in a Sn sample holder. After running several blanks and acetanalide standards, the sample was combusted in the analyzer at $1198 \mathrm{~K}$. The effluent gases were separated using a frontal chromatographic method and the percentages of $\mathrm{C}$, $\mathrm{H}$, and $\mathrm{N}$ were recorded. Each sample was analyzed at least twice, and the values obtained were used to estimate the carbon to tungsten atomic ratios $(\mathrm{C} / \mathrm{W})$. These ratios were determined assuming that whatever was not carbon, nitrogen or hydrogen was tungsten.

Nitrogen BET surface area and $\mathrm{O}_{2}$ chemisorption measurements were performed using a Quantasorb model QS-17 sorption analyzer. Approximately 100-200 mg of material was placed in a quartz sample holder. After reduction in $\mathrm{H}_{2}$ at $753 \mathrm{~K}$ for 3 hours, single point BET measurements were performed using a $28.9 \% \mathrm{~N}_{2}$ in $\mathrm{He}$ mixture (Scott) at $77 \mathrm{~K}$. Pulses of prepurified $\mathrm{N}_{2}$ (99.998\%, Air Products) were used to calibrate the volume adsorbed. This volume was then used to determine 
the surface area $\left(S_{\mathrm{g}}\right)$. The particle size, a semi-quantitative measure of the surface structure, was estimated from the surface area using the equation $D_{\mathrm{p}}=6 / \rho S_{\mathrm{g}}$ where $\rho$ is the density of the primary bulk phase of the material $\left(\rho=15.63 \mathrm{~g} / \mathrm{cm}^{3}\right.$ for WC and $17.15 \mathrm{~g} / \mathrm{cm}^{3}$ for $\mathrm{W}_{2} \mathrm{C}$ ). For the chemisorption measurements, calibrated volumes of $9.98 \% \mathrm{O}_{2}$ in $\mathrm{He}$ (Scott) were pulsed over the catalyst at room temperature until the surface was saturated. The volume of $\mathrm{O}_{2}$ that was not adsorbed, was measured and used to determine the chemisorbed volume. The chemisorbed volumes and the surface areas were reproducible over several runs. Averaged values were reported for all measurements.

\subsection{Activity and selectivity measurements}

Butane dehydrogenation activity and selectivity measurements were carried out using a $6 \mathrm{~mm}$ OD quartz U-tube reactor. Approximately 300-400 mg of catalyst was spread over a plug of quartz wool packed into the U-tube, and a chromelalumel ( $\mathrm{K}$ type) thermocouple was inserted directly into the catalyst bed. After $\mathrm{H}_{2}$ pretreatment at 753 for 3 hours, activity and selectivity measurements were carried out using $4 \% \mathrm{C}_{4} \mathrm{H}_{10}\left(99.998 \%\right.$, AGA) with a He balance or $4 \% \mathrm{C}_{4} \mathrm{H}_{10}, 36 \% \mathrm{He}$ with a $\mathrm{H}_{2}$ balance. The activity measurements were made at temperatures between 623 and $723 \mathrm{~K}$ after 4 to 6 hours on stream. The activities were reproducible to within $\pm 15 \%$. The reactions were run so that differential conditions prevailed; butane conversions during activity measurements were $\leq 5 \%$. We compared the catalytic properties of the carbides to those of a Pt-Sn $/ \gamma-\mathrm{Al}_{2} \mathrm{O}_{3}$ catalyst $(1.8 \% \mathrm{Na}$, $1.2 \% \mathrm{Sn}$, and $0.3 \% \mathrm{Pt}$ ) that was pretreated under similar conditions. Hereafter, $\mathrm{Pt}-$ $\mathrm{Sn} / \gamma-\mathrm{Al}_{2} \mathrm{O}_{3}$ is referred to as the $\mathrm{Pt}-\mathrm{Sn}$ catalyst.

The products were separated and analyzed using an HP 5890 Series II gas chromatograph (GC) equipped with a $3.05 \mathrm{~m}$ n-Octane/Porasil $\mathrm{C}$ packed column connected to a flame ionization detector. The HP ChemStation software was used to estimate product peak areas and retention times. The retention times and response factors were determined using standard alkane and alkene mixtures (Scott, \pm 2 $5 \%)$.

\section{Results}

\subsection{Characterization}

The primary bulk phases, as revealed by $\mathrm{XRD}$, were WC (hex) and $\mathrm{W}_{2} \mathrm{C}(\mathrm{hcp}$ ) (Table 1). The phase constituents did not change on use in butane dehydrogenation. All of the lower surface area materials contained WC, while the higher surface area materials contained primarily $\mathrm{W}_{2} \mathrm{C}$ with a small amount of $\mathrm{WC}$ in the bulk. The crystallite sizes of the carbides were independent of the synthesis conditions and precursor. A comparison of the crystallite and particle sizes suggested that the lower 
surface area materials contained polycrystalline aggregates. The higher surface area materials, on the other hand, contained small single crystallites. Preliminary transmission electron microscopy (TEM) verified that the lower surface area materials were polycrystalline and that the higher surface area materials were single crystallites. In both cases, the domain sizes from TEM were similar to the average crystallite sizes obtained from XRD. There was no simple correlation between the crystallite and particle sizes, and the materials did not show any texturing or preferred orientation.

The surface areas of the W carbides, which ranged from 4 to $39 \mathrm{~m}^{2} / \mathrm{g}$, depended on the synthesis conditions employed (Table 1). In general, the surface areas increased with increasing space velocity. This is consistent with previous studies which indicated that high space velocities were necessary for the synthesis of high surface area carbides and nitrides [13,18]. The addition of $\mathrm{H}_{2}$ to the feed mixture also resulted in an increased surface area. Hydrogen probably prohibited the deposition of graphitic carbon on the carbide surfaces. Lower $\mathrm{C} / \mathrm{W}$ ratios for carbides prepared with $\mathrm{H}_{2}$ in the feed support this proposition. The heating rate employed during carburization had only a modest effect on the resulting surface areas. This was quite surprising since one would expect the heating rate to influence the solidstate reaction selectivity and surface area [19]. The oxide precursor employed did not affect the resulting surface area. For similar conditions the TPC of tungsten trioxide (TO), tungstic acid (TA) and ammonium tungstate (AT) led to materials with similar surface areas and bulk structures. The carbide prepared via carburization of W nitride had a higher surface area than the carbides synthesized directly from the oxides under similar conditions.

Table 1

Summary of tungsten carbide synthesis conditions and bulk structural properties

\begin{tabular}{|c|c|c|c|c|c|c|c|c|}
\hline Catalyst code & $\beta(\mathrm{K} / \mathrm{h})$ & $\mathrm{H}_{2} / \mathrm{CH}_{4}$ & $\begin{array}{l}\mathrm{CH}_{4} \mathrm{SV} \\
\left(\mathrm{h}^{-1}\right)\end{array}$ & $S_{\mathrm{g}}\left(\mathrm{m}^{2} / \mathrm{g}\right)$ & $\begin{array}{l}\text { Particle size } \\
(\mathrm{nm})\end{array}$ & $\begin{array}{l}\text { Phase (s) } \\
\text { present }\end{array}$ & $\begin{array}{l}\text { Crystallite size } \\
(\mathrm{nm})\end{array}$ & $\mathrm{C} / \mathrm{W}$ \\
\hline WC-1 & 60 & 0 & 1.27 & 4.0 & 96 & WC & 12 & 1.85 \\
\hline WC-2 & 60 & 0 & 2.54 & 4.7 & 79 & WC & 12 & 1.75 \\
\hline WC-3 & 60 & 1.04 & 1.27 & 6.8 & 55 & WC & 16 & 1.41 \\
\hline WC-4 & 60 & 1.04 & 2.54 & 10.7 & 35 & WC & 12 & 1.45 \\
\hline WC-5 & 120 & 0 & 1.27 & 3.9 & 98 & WC & 13 & 1.72 \\
\hline WC-6 & 120 & 0 & 2.54 & 6.1 & 63 & WC & 12 & 1.72 \\
\hline WC-7 & 120 & 1.04 & 1.27 & 9.3 & 43 & WC & 16 & 1.40 \\
\hline WC-8 & 120 & 1.04 & 2.54 & 6.0 & 64 & WC & 14 & 1.57 \\
\hline $\mathrm{T}^{\mathbf{a}}$ & 75 & 0 & 1.01 & 19.5 & 20 & WC & 11 & 1.65 \\
\hline TO & 60 & 1.04 & 7.77 & 37.3 & 10 & $\mathrm{~W}_{2} \mathrm{C}$ & 13 & 0.97 \\
\hline $\mathrm{TA}^{\mathrm{b}, \mathrm{d}}$ & 60 & 1.04 & 7.77 & 38.7 & 10 & $\mathrm{~W}_{2} \mathrm{C}+\mathrm{WC}$ & 17 & 1.0 \\
\hline$A T^{c, d}$ & 60 & 1.04 & 7.77 & 36.6 & 10 & $W_{2} C+W C$ & 15 & 1.03 \\
\hline
\end{tabular}

${ }^{\text {a }}$ Carbide prepared from WN.

${ }^{b}$ Carbide prepared from $\mathrm{H}_{2} \mathrm{WO}_{4}$.

${ }^{c}$ Carbide prepared from $\left(\mathrm{NH}_{4}\right)_{10} \mathrm{~W}_{12} \mathrm{O}_{41} \cdot 5 \mathrm{H}_{2} \mathrm{O}$.

${ }^{d}$ Particle and crystallite sizes calculated assuming $\mathrm{W}_{2} \mathrm{C}$ bulk phase. 
Table 2

Chemisorptive properties of tungsten carbide catalysts

\begin{tabular}{lll}
\hline Catalyst code & Oxygen uptake $\left(\mu \mathrm{mol} \mathrm{O}_{2} / \mathrm{g}\right)$ & $N_{\text {oxygen }}\left(10^{12} \mathrm{O} / \mathrm{cm}^{2}\right)$ \\
\hline TO & 2.9 & 9.4 \\
TA & 2.7 & 8.4 \\
AT & 4.3 & 14.2 \\
$\mathrm{Pt}-\mathrm{Sn} / \gamma-\mathrm{Al}_{2} \mathrm{O}_{3}$ & 3.3 & - \\
\hline
\end{tabular}

Chemisorption was attempted on all of the materials, but only the higher surface area catalysts chemisorbed oxygen (Table 2 ). These materials had site densities that corresponded to oxygen surface coverages of ca. $1 \%$. Either the surfaces were blocked by graphitic carbon, ineffective in chemisorbing oxygen at room temperature, or residual oxygen at the surface after reduction prohibited chemisorption. Graphitic carbon has been reported to suppress the chemisorption of $\mathrm{O}_{2}, \mathrm{H}_{2}$ and $\mathrm{CO}$ on $\mathrm{W}$ carbides $[13,20]$. Oxygen has been reported to dissociate and strongly chemisorb onto $W$ carbides at room temperature $[14,21,22]$. In fact, oxygen coverages in excess of $100 \%$ have been observed for bulk $W$ carbides [14]. While the amount of oxygen in the material after reduction was not quantified, results from elemental analysis indicated that the $\mathrm{C} / \mathrm{W}$ ratios were in excess of unity for the lower surface area materials and near unity for the higher surface area materials (Table 1). The $\mathrm{C} / \mathrm{W}$ ratios expected for the stoichiometric equilibrium phases, WC and $\mathrm{W}_{2} \mathrm{C}$, are 1.0 and 0.5 , respectively. We have therefore concluded that the low uptake values on our $\mathrm{W}$ carbides were due primarily to the presence of graphitic carbon at the surface. Nevertheless, chemisorption does quantify the number of available sites so we used this value, when available, to normalize the reaction rates.

\subsection{Butane dehydrogenation over tungsten carbides}

\subsubsection{Dehydrogenation}

The tungsten carbides were active and selective for the dehydrogenation of butane. The Arrhenius plots in Fig. 1 show that, in general, the activities increased with increasing surface area. In Table 3, the kinetic properties of the carbides are compared to those of the Pt-Sn catalyst. Activities of the higher surface area W carbides (on an $\mathrm{O}_{2}$ uptake basis) were about an order of magnitude less than that of the Pt-Sn catalyst. The average carbide activation energy of $21 \pm 4 \mathrm{kcal} / \mathrm{mol}$ compared favorably with the value of $18 \pm 1 \mathrm{kcal} / \mathrm{mol}$ for the Pt-Sn catalyst. The butane conversion activation energies for all the catalysts were similar to those reported in the literature for dehydrogenation reactions [2,23].

Examples of the selectivities are given in Fig. 2. The selectivities over the carbide catalysts depended on the surface area and bulk structure. The primary products produced over the carbides were butenes. The higher surface area carbides produced small quantities of hydrogenolysis products. Selectivities over these materials were 
similar to those of the Pt-Sn catalyst. While the lower surface area carbides also produced primarily butenes, the distribution among these was different from those for the higher surface area carbides and the Pt-Sn catalyst. The higher surface area carbides and the Pt-Sn catalyst produced significant amounts of 2-butenes which probably resulted from the isomerization of 1-butenes. These catalysts appeared to have sites capable of catalyzing skeletal isomerization reactions.

\subsubsection{Dehydrogenation with $\mathrm{H}_{2}$}

The activities were generally higher in the presence of $\mathrm{H}_{2}$ compared to those in the absence of $\mathrm{H}_{2}$. This may have been due to prohibition of coke deposition, a common problem for dehydrogenation catalysts. Again, the activities over the

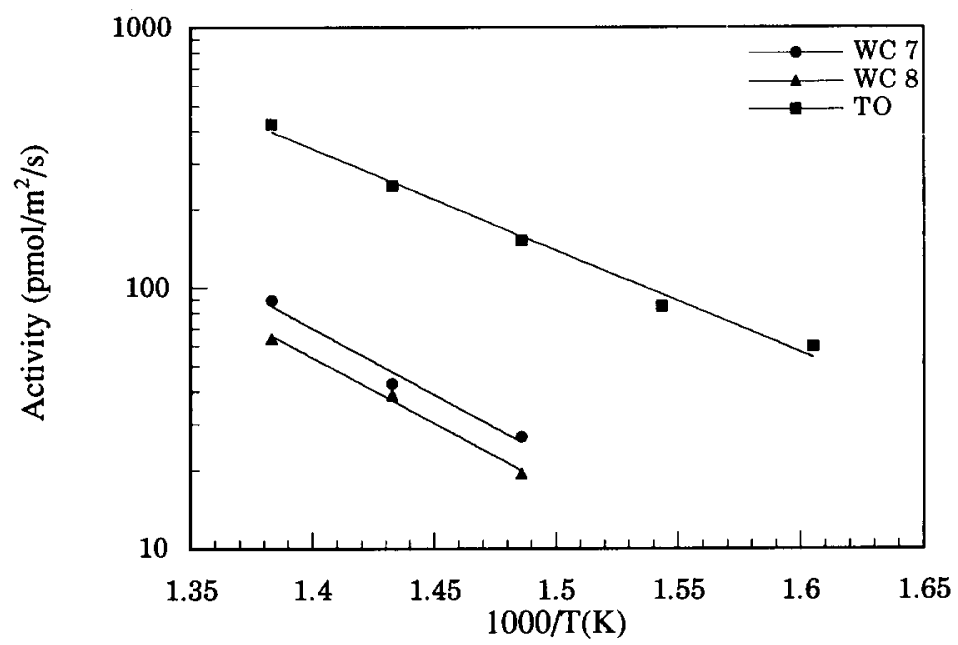

Fig. 1. Arrhenius plots of butane reaction activities over catalysts TO, WC-7 and WC-8. The surface areas of TO, WC-7 and WC-8 were $37.3,9.3$ and $6.0 \mathrm{~m}^{2} / \mathrm{g}$, respectively.

Table 3

Summary of butane dehydrogenation results

\begin{tabular}{lllll}
\hline \multirow{2}{*}{ Catalyst code } & Reaction rate $(\mathrm{pmol} / \mathrm{g} / \mathrm{s})$ & Activity at $723 \mathrm{~K}$ & \multirow{2}{*}{$\Delta E_{\text {act }}(\mathrm{kcal} / \mathrm{mol})$} \\
& & $\left(\mathrm{pmol} / \mathrm{m}^{2} / \mathrm{s}\right)$ & $\left(\mathrm{mmol} / \mathrm{mol} \mathrm{O}_{2} / \mathrm{s}\right)$ & \\
\hline WC-1 & 461 & 115 & - & 17 \\
WC-2 & 568 & 121 & - & 22 \\
WC-3 & 481 & 71 & - & 14 \\
$W C-4$ & 3123 & 292 & - & 27 \\
WC-5 & 469 & 120 & - & 22 \\
WC-6 & 602 & 99 & - & 21 \\
WC-7 & 836 & 90 & - & 23 \\
WC-8 & 440 & 73 & - & 23 \\
T & 410 & 21 & - & 26 \\
TO & 15999 & 429 & 5.5 & 21 \\
TA & 4541 & 117 & 1.7 & 25 \\
AT & 12269 & 335 & 2.9 & 16 \\
Pt-Sn $/ \gamma-\mathrm{Al}_{2} \mathrm{O}_{3}$ & $2.75 \times 10^{5}$ & - & 83.5 & 18 \\
\hline
\end{tabular}




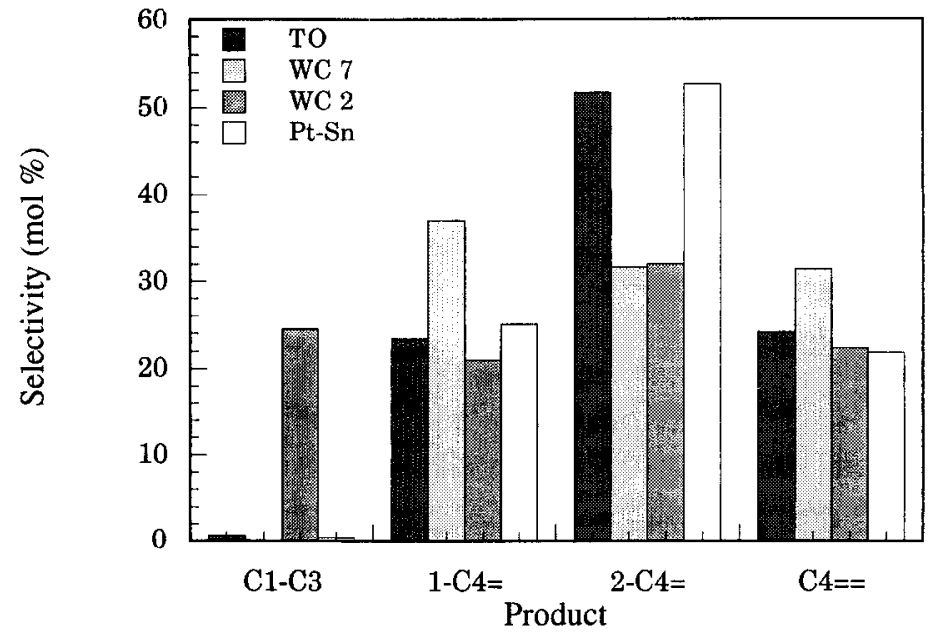

Fig. 2. Examples of selectivities from butane reactions at $723 \mathrm{~K} . \mathrm{C}_{n}$ denotes an $n$ carbon hydrocarbon. The $=$ sign denotes a double bond. The surface areas of TO, WC-7 and WC-2 were $37.3,9.3$ and $4.7 \mathrm{~m}^{2} / \mathrm{g}$, respectively.

carbides increased with increasing surface area (Fig. 3). The activities of the carbides are compared to those of the Pt-Sn catalyst in Table 4. The low surface area materials were 1 to 2 orders of magnitude less active than the Pt-Sn catalyst, while the higher surface area carbides had activities (on an $\mathrm{O}_{2}$ uptake basis) that were comparable or superior to that of the Pt-Sn catalyst. These results suggested that the characteristics of active sites in the tungsten carbides were similar to those in the Pt based catalyst, as have been previously reported [1-8]. The average apparent activation energy of $23 \pm 5 \mathrm{kcal} / \mathrm{mol}$ was within experimental error of the value for the Pt-Sn catalyst $(28 \pm 2 \mathrm{kcal} / \mathrm{mol})$.

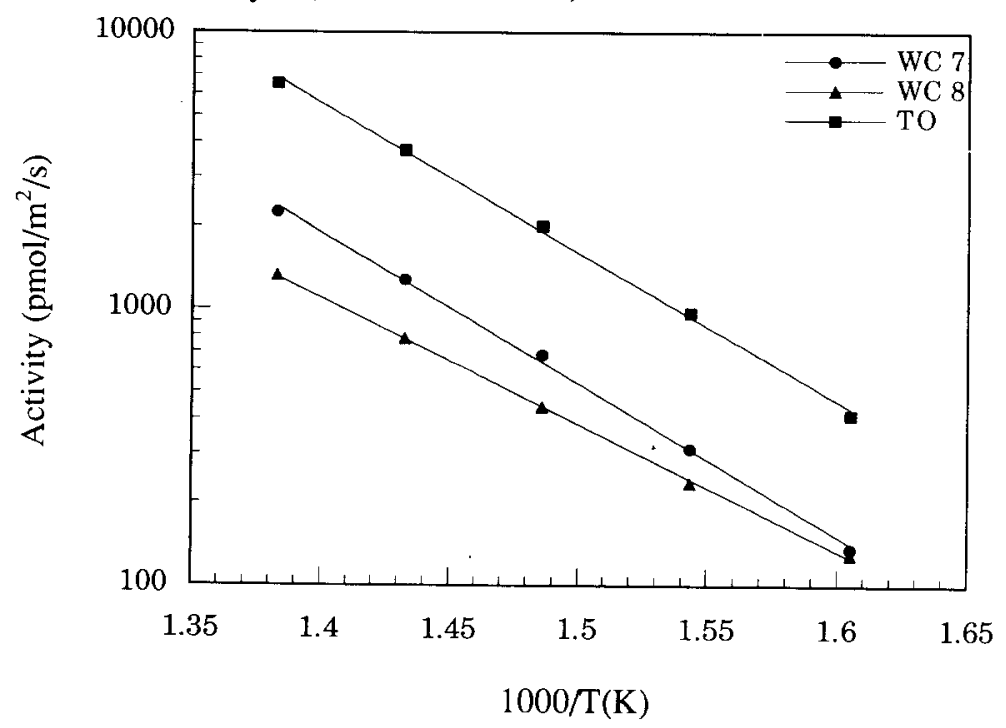

Fig. 3. Arrhenius plots of butane reaction activities in $\mathrm{H}_{2}$ over catalysts TO, WC-7 and WC-8. The surface areas of TO, WC-7 and WC-8 were $37.3,9.3$ and $6.0 \mathrm{~m}^{2} / \mathrm{g}$, respectively. 
Table 4

Summary of butane dehydrogenation in $\mathrm{H}_{2}$ results

\begin{tabular}{lllll}
\hline Catalyst code & Reaction rate $(\mathrm{nmol} / \mathrm{g} / \mathrm{s})$ & \multicolumn{2}{c}{$\Delta E_{\text {act }}(\mathrm{kcal} / \mathrm{mol})$} \\
\cline { 3 - 4 } & & $\left(\mathrm{nmol} / \mathrm{m}^{2} / \mathrm{s}\right)$ & $\left(\mathrm{mmol} / \mathrm{mol} \mathrm{O}_{2} / \mathrm{s}\right)$ & \\
\hline WC-1 & 10 & 2.5 & - & 22 \\
$W C-2$ & 44 & 9.4 & - & 24 \\
WC-3 & 3 & 0.4 & - & 28 \\
WC-4 & 52 & 4.9 & - & 22 \\
WC-5 & 43 & 11.1 & - & 28 \\
WC-6 & 14 & 2.3 & - & 24 \\
WC-7 & 21 & 2.2 & - & 25 \\
WC-8 & 8 & 1.3 & - & 21 \\
T & 10 & 0.5 & - & 18 \\
TO & 244 & 6.5 & 84.1 & 25 \\
TA & 170 & 4.4 & 63.0 & 18 \\
AT & 188 & 5.1 & 43.7 & 25 \\
Pt-Sn $/ \gamma-\mathrm{Al}_{2} \mathrm{O}_{3}$ & 194 & - & 58.8 & 28 \\
\hline
\end{tabular}

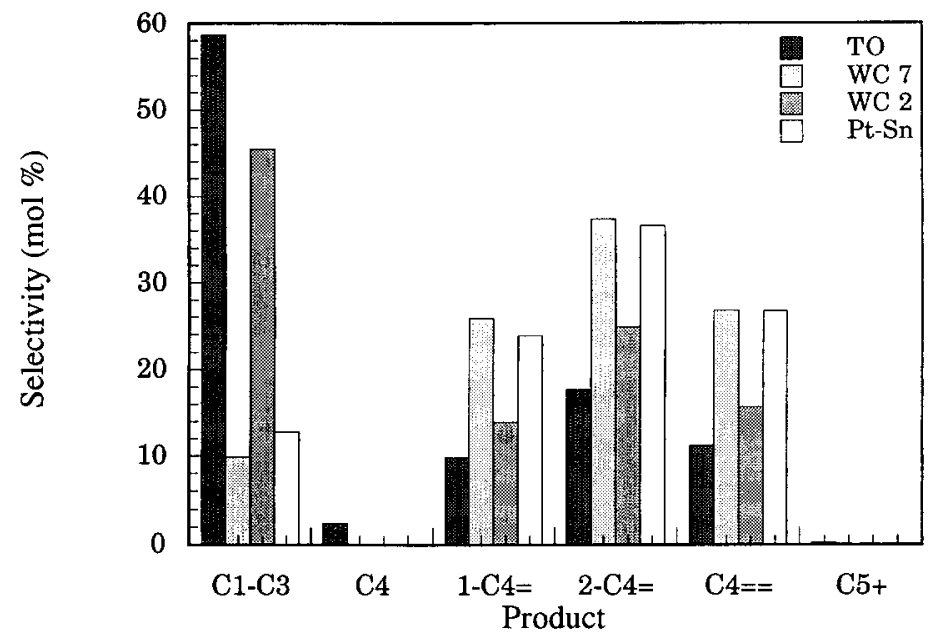

Fig. 4. Examples of selectivities during butane reactions in $\mathrm{H}_{2}$ at $723 \mathrm{~K}$. $\mathrm{C}_{n}$ denotes an $n$ carbon hydrocarbon. The $=$ sign denotes a double bond. The surface areas of TO, WC-7 and WC-2 were $37.3,9.3$ and $4.7 \mathrm{~m}^{2} / \mathrm{g}$, respectively.

The selectivities in the presence of $\mathrm{H}_{2}$ were different than those in the absence of $\mathrm{H}_{2}$, although in both cases, the selectivities depended on the surface area and bulk structure (Fig. 4). The higher surface area materials were very active for hydrogenolysis. Small quantities of isomerization products, $\mathrm{i}-\mathrm{C}_{4} \mathrm{H}_{10}$ and $\mathrm{i}-\mathrm{C}_{5} \mathrm{H}_{12}$, were also detected over these materials. Selectivities over the higher surface area materials were also different from those over the $\mathrm{Pt}-\mathrm{Sn}$ catalyst. With the exception of WC-2, the lower surface area carbides were not very active for hydrogenolysis. 


\section{Discussion}

Of the synthesis variables studied, the space velocity and feed composition (namely the $\mathrm{H}_{2}$ content) had the most significant effects on the carbide surface areas and structures. These variables can regulate the solid-state reaction pathways [24]. Increasing the space velocity led to an increase in the surface area. Oyama et al. [13] reported similar behavior during the preparation of $\mathrm{Mo}_{2} \mathrm{C}$. The increase in surface area may have been caused by changes in the composition of the gas at the reaction interface. A plausible explanation is that high space velocities removed $\mathrm{H}_{2} \mathrm{O}$ vapor from the reaction interface. Water vapor, even in small concentrations, can cause hydrothermal sintering $[25,26]$. Water might also inhibit the solid-state reactions leading to higher surface area carbides. In either case, high space velocities would minimize the amount of $\mathrm{H}_{2} \mathrm{O}$ and other volatile reaction products near the surface [18]. The similarity between the surface areas and bulk structures of the TO, TA and AT carbides suggested that there was no effect of precursor structure and their solid-state reaction intermediates were similar. This intermediate did not appear to be $\mathrm{WO}_{2}$. High temperature X-ray diffraction results showed that carburization of $\mathrm{WO}_{3}$ through a $\mathrm{WO}_{2}$ intermediate led to materials with low surface areas. It has been reported that the nitridation of $\mathrm{MoO}_{3}$ through $\mathrm{MoO}_{2}$ also results in low surface area nitrides $[9,23,27]$. The primary function of $\mathrm{H}_{2}$ in the $\mathrm{CH}_{4}$ feed appeared to be inhibition of the growth of graphitic carbon at the surface [15]. While the exact amount of $\mathrm{H}_{2}$ necessary to prepare materials without carbon at the surface is unknown, it is clear that $\mathrm{H}_{2}$ facilitated the evolution of high surface areas.

The catalytic properties of the $\mathrm{W}$ carbides were different from those reported in the literature $[2,5,6,8]$. We found that the low surface area $W$ carbides were selective for butane dehydrogenation, while the higher surface area materials were selective for hydrogenolysis. Leclercq et al. [2] reported that a series of low surface area $\mathrm{W}$ carbides were active primarily for butane hydrogenolysis (at $623 \mathrm{~K}$ using a $\mathrm{H}_{2} / \mathrm{C}_{4} \mathrm{H}_{10}$ partial pressure ratio of 9 ). These materials, which were prepared isothermally from reduced tungstic acid and acetylene black, also catalyzed the isomerization of butane. Ribeiro et al. [5,6] prepared WC $\left(30 \mathrm{~m}^{2} / \mathrm{g}\right)$ and $\beta-\mathrm{W}_{2} \mathrm{C}$ $\left(100 \mathrm{~m}^{2} / \mathrm{g}\right)$ via the TPC of $\mathrm{WO}_{3}$ and reported that these materials catalyzed neopentane and hexane hydrogenolysis. For the neopentane reactions (at $490 \mathrm{~K}$ using a $\mathrm{H}_{2} / \mathrm{C}_{5} \mathrm{H}_{10}$ ratio of 9 ), there was a 30 fold difference between the activities over these catalysts. Activities for hexane hydrogenolysis (at $430 \mathrm{~K}$ using a $\mathrm{H}_{2}$ / $\mathrm{C}_{6} \mathrm{H}_{14}$ ratio of 16) were similar for the two materials. Ledoux et al. [8] reacted $\mathrm{WO}_{2}$ vapors with activated carbon under vacuum at high temperatures to prepare high surface area carbides. They reported that these materials were active for hexane hydrogenolysis and isomerization (at $723 \mathrm{~K}$ using a $\mathrm{H}_{2} / \mathrm{C}_{6} \mathrm{H}_{14}$ ratio of 151 ). Our results and those in the literature suggest that the character of the active sites is a strong function of the synthesis conditions. The ratio of hydrogen to hydrocarbon in the feed also appears to affect the catalytic properties as evidenced by the wide variation in catalytic activities and selectivities. 


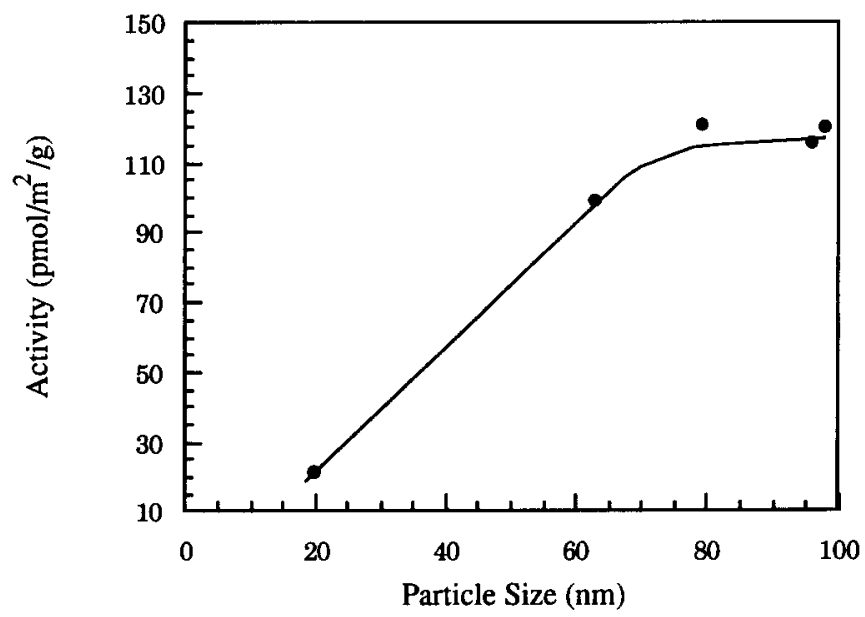

Fig. 5. Schematic showing the relationship between the butane dehydrogenation activity and particle size. These $\mathrm{W}$ carbides were prepared using pure $\mathrm{CH}_{4}$.

Very clear trends between the catalytic and structural properties were observed when the $\mathrm{W}$ carbides were grouped based on the conditions used to prepare the materials. Fig. 5 shows the dehydrogenation activities over the catalysts prepared using pure $\mathrm{CH}_{4}$. The $\mathrm{C}_{4} \mathrm{H}_{10}$ dehydrogenation activities in the absence of $\mathrm{H}_{2}$ increased with particle size up to ca. $80 \mathrm{~nm}$, then leveled off. No clear trends for the activity in $\mathrm{C}_{4} \mathrm{H}_{10}-\mathrm{H}_{2}$ mixtures with particle size were apparent for these catalysts. Nevertheless, the results suggested that the catalytic properties of $\mathrm{W}$ carbides varied with the surface structure and stoichiometry.

Dehydrogenation activities over the carbides prepared using $\mathrm{CH}_{4}-\mathrm{H}_{2}$ mixtures are shown in Fig. 6 and Fig. 7. The materials with particle sizes greater than $30 \mathrm{~nm}$

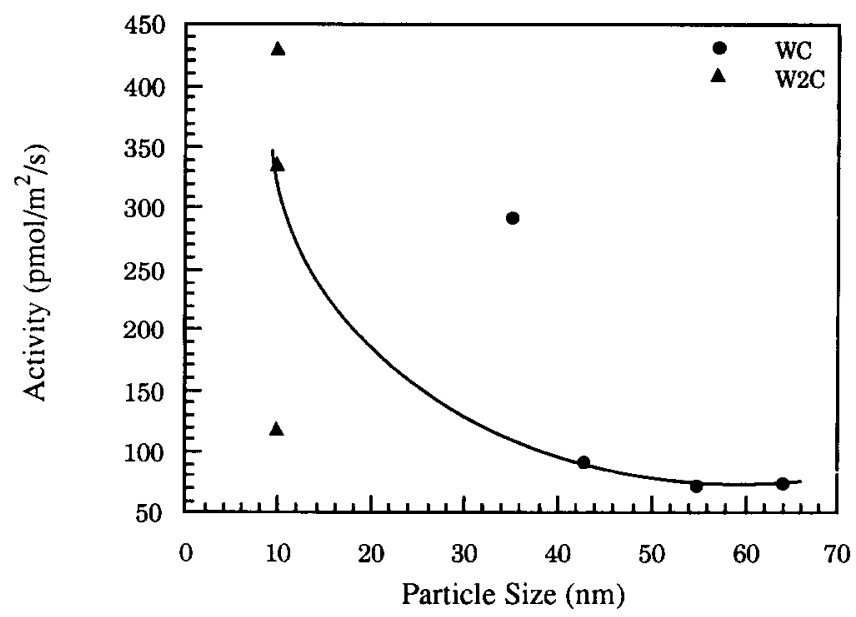

Fig. 6. Schematic showing the relationship between the butane dehydrogenation activity and particle size. These W carbides were prepared using $\mathrm{CH}_{4}-\mathrm{H}_{2}$ mixtures. 


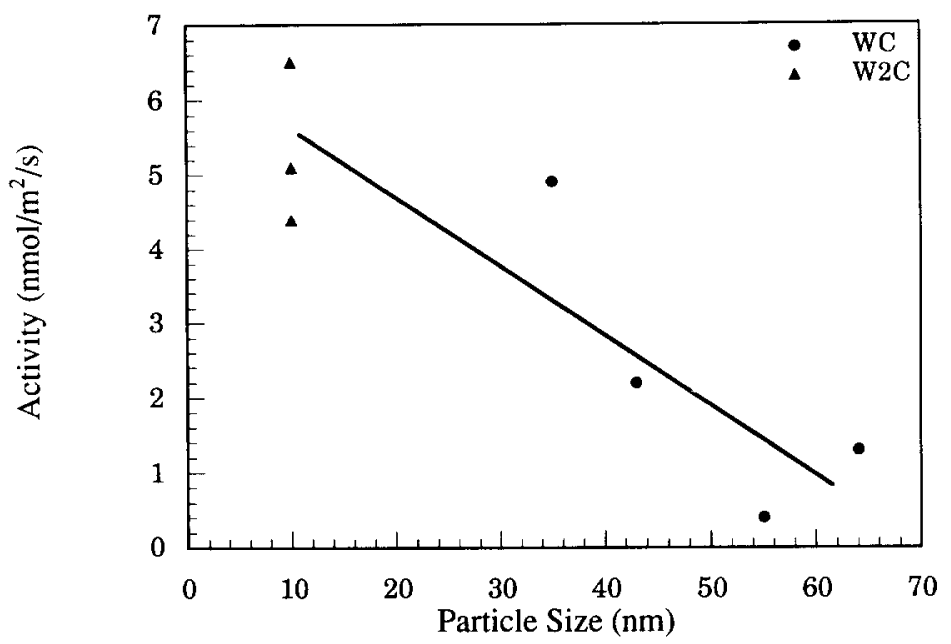

Fig. 7. Schematic showing the relationship between the butane dehydrogenation activity in the presence of $\mathrm{H}_{2}$ and particle size. These $\mathrm{W}$ carbides were prepared using $\mathrm{CH}_{4}-\mathrm{H}_{2}$ mixtures.

contained only WC in the bulk, while those with particle sizes less than $30 \mathrm{~nm}$ contained either $\mathrm{W}_{2} \mathrm{C}$ or mixtures of $\mathrm{W}_{2} \mathrm{C}$ and $\mathrm{WC}$. The butane dehydrogenation activities, without and with $\mathrm{H}_{2}$ in the reactant feed, increased with decreasing particle size. Despite the different bulk structures, a single line adequately described all of the data including that for the $\mathrm{W}_{2} \mathrm{C}$ containing catalysts. The reasons why $\mathrm{W}_{2} \mathrm{C}$ and $\mathrm{WC}$ follow similar trends with particle size are not clear, however, it is noteworthy that $\mathrm{W}_{2} \mathrm{C}$ and $\mathrm{WC}$ are hexagonal structures.

The apparent structure-sensitivity of butane dehydrogenation over the $\mathrm{W}$ carbides was not expected. Structure-sensitivity is typically manifested for particles smaller than ca. $10 \mathrm{~nm}$ [28]. For metals it is usually associated with variations in the reaction rates with the crystallographic faceting of the surface. However, for $\mathrm{W}$ carbides, one must also consider the influence of surface stoichiometry and the presence of more than one phase. Given the observed variations in the phase constituents with surface area, it is plausible that the near surface $\mathrm{C} / \mathrm{W}$ stoichiometry was a function of the particle size, even for the relatively large particles in the $\mathrm{W}$ carbides. The carbides also appeared to contain significant amounts of graphitic carbon at the surface although one would not expect the catalysis to occur on carbon. It is possible that the character of the unblocked surface is affected by the size of the carbide particles. Structure-sensitivity is more common for hydrogenolysis than for dehydrogenation reactions [28]. Lee et al. [29] reported that the butane hydrogenolysis activity over $\mathrm{Mo}_{2} \mathrm{C} / \mathrm{Al}_{2} \mathrm{O}_{3}$ increased with increasing loading. They also found that the hydrogenolysis activity over hexagonal $\mathrm{Mo}_{2} \mathrm{C}$ was greater than that over cubic $\alpha-\mathrm{MoC}_{1-x}$. The smaller $\alpha-\mathrm{MoC}_{1-x}$ particles had higher turnover frequencies than the larger ones. These results implied the structuresensitivity of hydrogenolysis over Mo carbides. Dehydrogenation has typically been found to be structure-insensitive over noble metals like Pt $[28,30]$. 


\section{Conclusions}

The properties of a series of $\mathrm{W}$ carbides prepared by the temperature-programmed carburization method were strong functions of the synthesis conditions employed. The most influential synthesis parameters were the space velocity and the $\mathrm{H}_{2} / \mathrm{CH}_{4}$ ratio. Higher space velocities resulted in materials with high surface areas presumably because of the removal of $\mathrm{H}_{2} \mathrm{O}$ and other volatiles from the reaction interface. While the mechanisms for inhibition of graphitic carbon deposition or its removal are unclear, the presence of $\mathrm{H}_{2}$ in the feed mixture reduced the amount of carbon in the materials and increased their surface areas. The higher surface area materials contained $\mathrm{W}_{2} \mathrm{C}$ or a mixture of $\mathrm{W}_{2} \mathrm{C}$ and $\mathrm{WC}$, while the lower surface area materials contained WC. The lower surface area carbides contained particles that appeared to be polycrystalline aggregates with no apparent preferential orientation. Oxygen chemisorption was only achieved on the higher surface area materials. We believe that chemisorption was inhibited by the presence of graphitic carbon at the surface.

The $\mathrm{W}$ carbides were active for the dehydrogenation of butane in the presence and absence of $\mathrm{H}_{2}$. The higher surface area materials were as active as a Pt-Sn catalyst in the presence of $\mathrm{H}_{2}$. The selectivities of the lower surface area materials were similar to those of the Pt-Sn catalyst. In the absence of $\mathrm{H}_{2}$, the carbides were 2 to 4 orders of magnitude less active than the Pt-Sn catalyst. While the primary reaction products were alkenes, the product distributions over the carbides varied with surface area. The higher surface area carbides also catalyzed butane hydrogenolysis in addition to butane dehydrogenation.

Dehydrogenation over the $\mathrm{W}$ carbides appeared to be structure-sensitive since the activity varied with changes in the surface area and particle size. We believe that these responses were due to variations in the surface stoichiometry/composition. We are currently investigating the influences of surface structure using TEM.

\section{Acknowledgements}

This research was sponsored by a grant from the Amoco Oil Company. The Pt$\mathrm{Sn} / \gamma-\mathrm{Al}_{2} \mathrm{O}_{3}$ catalyst was supplied by Dr. Bruce Alexander of the Amoco Oil Company. The authors are grateful to Cecelia Duster for assistance with the sorption measurements. 


\section{References}

[1] G.V. Samsonov, T.G. Bulankova, P.A. Khodak, E.M. Preshedromirskaya, V.S. Sinelnikova and V.M. Sleptsov, Kinet. Katal., 10 (1969) 863.

[2] L. Leclercq, M. Provost, H. Pastor and G. Leclercq, J. Catal. 117 (1989) 384.

[3] Z. Gao and D.Y. Qin, Chin. J. Chem., 3 (1990) 207.

[4] R.B. Levy and M. Boudart, Science, 181 (1973) 547.

[5] F.H. Ribeiro, R.A. Dalla Betta, M. Boudart, J. Baumgartner and E. Iglesia, J. Catal., 130 (1991) 86.

[6] F.H. Ribeiro, M. Boudart, R.A. Dalla Betta and E. Iglesia, J. Catal., 130 (1991) 498.

[7] V. Keller, M. Cheval, M. Vayer, R. Ducros and G. Maire, Catal. Lett., 10 (1991) 137.

[8] M.J. Ledoux, C.P. Huu, J. Guille and H. Dunlop, J. Catal., 134 (1992) 383.

[9] L.E. Toth, Transition Metal Carbides and Nitrides, Academic Press, New York (1971).

[10] E.J. Ko and R.J. Madix, J. Catal., 73 (1982) 161.

[11] A.L. Kharlamov, V.P. Krivitskii and N.D. Lemershko, React. Kinet. Catal. Lett., 17 (1981) 63.

[12] P.N. Ross and P. Stonehart, J. Catal., 48 (1977) 42.

[13] S.T. Oyama, J.C. Schlatter, J.E. Metcalfe, III and J.M. Lambert, Jr., Ind. Eng. Chem. Res., 27 (1988) 1639.

[14] F.H. Ribeiro, R.A. Dalla Betta, G.J. Guskey and M. Boudart, Chem. Mater., 3 ( 1991 ) 805.

[15] L. Volpe and M. Boudart, J. Solid State Chem., 59 (1985) 348.

[16] W.F. McClune (Editor), Powder Diffraction File, Alphabetical Index Inorganic Materials, International Centre for Diffraction Data: Swarthmore, PA (1991)

[17] B.D. Cullity, Elements of X-ray Diffraction, Addison-Wesley, New York (1978).

[18] J.S. Lee, L. Volpe, F.H. Ribeiro and M. Boudart, J. Catal., 112 (1988) 44.

[19] J. Choi, J.R. Brenner, C.W. Colling, B.G. Demczyk, J. Dunning and L.T. Thompson, Catal. Today, 15 (1992) 201.

[20] M. Boudart, J. Catal., 103 (1987) 30.

[21] P.M. Stefan, Ph.D. Thesis Stanford University (1983).

[22] E.J. Ko and R.J. Madix, J. Phys. Chem., 85 (1981) 4919.

[23] S. Carra and L. Forni, Catal. Rev., 5 (1971) 159.

[24] J. Choi, R.L. Curl and L.T. Thompson, J. Catal., 146 (1994) 218.

[25] P.J. Anderson and P.L. Morgan, Trans. Faraday Soc., 60 (1964) 930.

[26] R.F. Horlock, P.L. Morgan and P.J. Anderson, Trans. Faraday Soc., 59 (1963) 721.

[27] C.H. Jaggers, J.N. Michaels and A.M. Stacy, Chem. Mater., 2 (1990) 150

[28] M. Boudart and G. Djega-Mariadassou, Kinetics of Heterogeneous Catalytic Reactions, Princeton University Press, Princeton, NJ (1984).

[29] J.S. Lee, S. Locatelli, S.T. Oyama and M. Boudart, J. Catal., 125 (1990) 157.

[30] J.H. Sinfelt, Catal. Rev. Sci. Eng., 9 (1974) 147. 